\title{
Formation and distribution of disinfection by-products during chlorine disinfection in the presence of bromide ion
}

\author{
LI Bo, QU JiuHui†, LIU HuiJuan \& ZHAO Xu \\ State Key Laboratory of Environmental Aquatic Chemistry, Research Center for Eco-Environmental Sciences, Chinese Academy of \\ Sciences, Beijing 100085, China
}

The influences of contact time and $\mathrm{pH}$ value on the formation and distribution of four species of trihalomethanes and five species of haloacetic acids during chlorination in the presence of bromine were investigated. Results showed that the distribution of molar fraction of trihalomethanes varied with contact time due to the change of bromide ion concentration during chlorination. Most of the trihalomethanes comprising bromine-containing species and the favored products of the haloacetic acids were chlorine-containing species after $24 \mathrm{~h}$ of chlorination. The extent of bromine incorporation in trihalomethanes and haloacetic acids both decreased with time. The contact time also had influence on the formation rate of different species of haloacetic acids. The formation and distribution of trihalomethanes and haloacetic acids strongly depended on the chlorination pH value. All of the trihalomethanes species formation increased with the increase of $\mathrm{pH}$ value except the bromoform that had not been detected. The molar fraction of bromodichloromethane and dibromochloromethane containing bromine increased with $\mathrm{pH}$ value while chloroform without bromine decreased. Under the $\mathrm{pH}$ range studied in this experiment, the predominant haloacetic acids species were trichloroacetic acid and dichloroacetic acid which all decreased with the increase of $\mathrm{pH}$ value and the level of TCAA was higher than that of DCAA.

bromine, residual chlorine, chlorination, THMs, HAAs

Chlorination is widely utilized in drinking water disinfection due to its broad-spectrum germicidal efficiency, low cost and convenient practices ${ }^{[1]}$. However, chlorine reacts readily with natural organic material (NOM) in water, such as humic acid, to form disinfection by-products (DBPs) that have been identified as potentially carcinogenic reagents ${ }^{[2]}$. Bromide is usually detected in the ground water of coastal areas due to seawater intrusion $^{[3]}$. The presence of bromide changes the chlorinated reaction pathways. Bromide is oxidized by chlorine to produce hypobromous acid ( $\mathrm{HOBr}$ ) and affects both DBPs formation and distribution ${ }^{[4]}$. Hypobromous acid reacts more rapidly than hypochlorous acid with organic compounds and brominated organic compounds are more mutagenic and toxic compared with the chlorinated ones ${ }^{[5]}$.

Trihalomethanes (THMs) and haloacetic acids (HAAs) have been reported to be two of the most important $\mathrm{DBPs}^{[6]}$. There are total of four THMs (chloroform $(\mathrm{CF})$, bromodichloromethane (BDCM), dibromochloromethane (DBCM) and bromoform (BF)) and nine HAAs (monochloroacetic acid (MCAA), dichloroacetic acid (DCAA), trichloroacetic acid (TCAA), monobromoacetic acid (MBAA), dibromoacetic acid (DBAA), tribromoacetic acid (TBAA), bromochloroacetic acid (BCAA), bromodi-

Received November 22, 2007; accepted March 6, 2008

doi: $10.1007 / \mathrm{s} 11434-008-0336-\mathrm{z}$

†Corresponding author (email: jhqu@rcees.ac.cn)

Supported by the National Natural Science Foundation of China for Creative Research Groups (Grant No. 50621804) and International Copper Association Ltd. (Grant No. H-AS-04-03) 
chloroacetic acid (BDCAA) and dibromochloroacetic acid (DBCAA)) containing chlorine and bromine formed upon chlorination of waters containing bromide $\left(\mathrm{Br}^{-}\right)$. Concerns about health risks associated with DBPs in drinking water have prompted several industrialized countries such as USA to establish rigorous levels for THM and HAA concentrations. The United States Environmental Protection Agency (EPA) set the current maximum contaminant level of $80 \mu \mathrm{g} / \mathrm{L}$ for THM. Among the nine HAAs species, only five of them (the sum of MCAA, DCAA, TCAA, MBAA and DBAA) were regulated and the current maximum concentration level for $\mathrm{HAA}_{5}$ is $60 \mu \mathrm{g} / \mathrm{L}$.

The objective of this study is to assess the effects of contact time and $\mathrm{pH}$ value on the formation and distribution of four species of THMs and five species of HAAs during chlorination of waters containing bromide. This paper presents the results with respect to the formations of DBPs speciation containing chlorine and bromide respectively under different contact time and $\mathrm{pH}$ value.

\section{Experimental}

\subsection{Chemicals and glassware}

Humic acid (HA) was purchased from Tianjin Chemical Reagent Development Center and used as NOM sources. The humic acid stock solution was prepared by dissolving an amount of the material into deionized water in base condition $(\mathrm{pH}=12)$ and then filtered by a piece of $0.45 \mu \mathrm{m}$ filter paper. The concentration of HA was analyzed using a Multi N/C 3000 TOC analyzer (Analytikjena).

Stock solutions of chlorine were prepared by diluting a commercial solution of sodium hypochlorite ( $\mathrm{NaOCl}>10 \%$ available chlorine), stored at $4^{\circ} \mathrm{C}$ in the dark and periodically standardized by N,N-diethyl-pphenylenediamine (DPD) methods.

Four trihalomethanes standard solutions (CF, BDCM, DBCM, BF) were purchased from the National Research Centre for Certified Reference Materials (NRCCRM) of China. Standard solutions of MCAA, MBAA and DBAA were obtained from Ultra Scientific. Standard solutions of DCAA (>99\%) and TCAA (>99\%) were obtained from Acros Organics.

Preparation of sample bottles included washing with detergent, rinsing with tap water and deionized water at least three times and placing in an oven at $500^{\circ} \mathrm{C}$ for $4 \mathrm{~h}$.
Preparation of other glassware included washing with detergent, rinsing with tap water, dunking with chromate lotion at least $30 \mathrm{~min}$, rinsing with deionized water and drying at room temperature.

\subsection{Methods}

After adding humic acid stack solution and $\mathrm{KBr}$ solution to the tap water treated by activated carbon, a certain volume of sodium hypochlorite stock solution was added, and $\mathrm{pH}$ value was adjusted with hydrochloric acid and sodium hydroxide. Conditions used in the chlorination procedure were $\mathrm{pH}=8.0,5.6 \mathrm{mg} / \mathrm{L}$ of $\mathrm{TOC}$, $20 \mathrm{mg} / \mathrm{L}\left(\right.$ as $\mathrm{Cl}_{2}$ ) chlorine dose and $0.2 \mathrm{mg} / \mathrm{L}$ of bromine. After the water was introduced, the glass pipes were sealed and lay in incubator at $20^{\circ} \mathrm{C}$ in the dark. Water samples were taken from different pipes after 1, 2, 4, 8, $12,24 \mathrm{~h}$ and measured the residual chlorine, THMs (CF, BDCM, DBCM, BF) and HAAs (MCAA, MBAA, DCAA, TCAA, TBAA). In the case of determining the effect of $\mathrm{pH}(5.0,6.0,7.0,8.0$ and 9.0), the water samples were withdrawn from different pipes with different $\mathrm{pH}$ values after $15 \mathrm{~h}$ immersion and then measured residual chlorine, THMs and HAAs. The experiments were repeated three times (each) and the averages were reported.

\subsection{Analysis procedures}

A gas chromatograph (Agilent 6890N Series, America) with an electron capture detector was used for determining THMs and HAAs using USEPA method 551.1 ${ }^{[7]}$ and $552.3^{[8]}$, respectively. Separation of species was achieved with a HP-5 fused silica capillary column (30 m $\times 0.32 \mathrm{~mm} \times 0.25 \mu \mathrm{m}$ ) under the temperature program (i) THMs: held at $35^{\circ} \mathrm{C}$ for $4 \mathrm{~min}$, ramped to $100^{\circ} \mathrm{C}$ at $10^{\circ} \mathrm{C} / \mathrm{min}$ and held $3 \mathrm{~min}$; (ii) HAAs: held at $35^{\circ} \mathrm{C}$ for 4 min, ramped to $65^{\circ} \mathrm{C}$ at $2^{\circ} \mathrm{C} / \mathrm{min}$. The collection and analysis of data were obtained by Agilent Chem Station. Residual chlorine was eliminated by the addition of sodium thiosulfate immediately after collection.

Chlorine was measured using the N,N-diethyl-pphenylenediamine (DPD) by UV-spectrophotometer at $510 \mathrm{~nm}$.

\section{Results and discussion}

\subsection{Effect of reaction time on formation and dis- tribution of THMs}

Investigation of the impact of reaction time on DBPs 

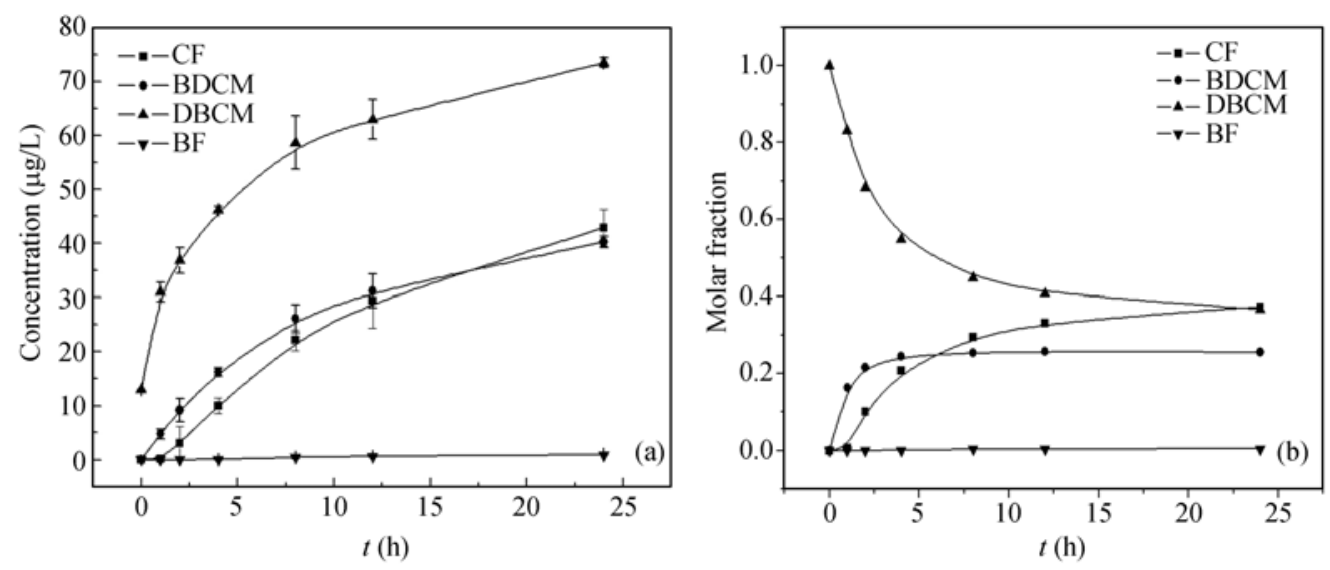

Figure 1 Effect of reaction time on formation and distribution of THMs species.

formation is critical to determining the final concentrations to which people could be exposed ${ }^{[9]}$. Figure 1 shows the effect of reaction time on the formation of four species of THMs. As shown in Figure 1, four THMs all increased with reaction time. The formation rate of THMs at $12 \mathrm{~h}$ was in the order of DBCM (62.9 $\mu \mathrm{g} / \mathrm{L})>\mathrm{BDCM}(31.2 \mu \mathrm{g} / \mathrm{L})>\mathrm{CF}(29.4 \mu \mathrm{g} / \mathrm{L})>\mathrm{BF}(0.6$ $\mu \mathrm{g} / \mathrm{L})$. The major species formed was brominated THMs ( $71.8 \%$ of the total THMs). It should be noted that the production rate of four species was different. It is evident that detectable quantities of DBCM were formed $(13.0 \mu \mathrm{g} / \mathrm{L})$ immediately after the chlorination. $4.8 \mu \mathrm{g} / \mathrm{L}$ of BDCM occurred after $1 \mathrm{~h}$ and only 3.1 $\mu \mathrm{g} / \mathrm{L}$ of $\mathrm{CF}$ yielded after $2 \mathrm{~h}$ of contact. It is generally accepted that $\mathrm{HOBr}$ reacts with $\mathrm{NOM}$ faster than $\mathrm{HOCl}$. Even at lower bromide concentration, brominated THM species can be produced ${ }^{[10]}$. Therefore, brominated THM formed in water containing bromine ion immediately after chlorination while $\mathrm{CF}$ formed only after $2 \mathrm{~h}$.

Figure 1(b) illustrates the molar fraction of each THM species as functions of reaction time. As shown, the molar fraction of CF and BDCM increased with time, while that of DBCM decreased. The concentration of $\mathrm{BF}$ was always at low level during $24 \mathrm{~h}$.

To further explain the effect of reaction time on molar fraction of four THMs, the influence of bromine ion concentration on THMs formation and distribution at a chlorine dose of $17 \mathrm{mg} / \mathrm{L}$ chlorine was investigated, as depicted in Figure 2. The formation of $\mathrm{CF}$ and BDCM decreased with the increase of $\mathrm{Br}^{-}$dose, while $\mathrm{BF}$ formation increased. The yield of DBCM increased initially and then decreased, with the peaks occurring at bromide

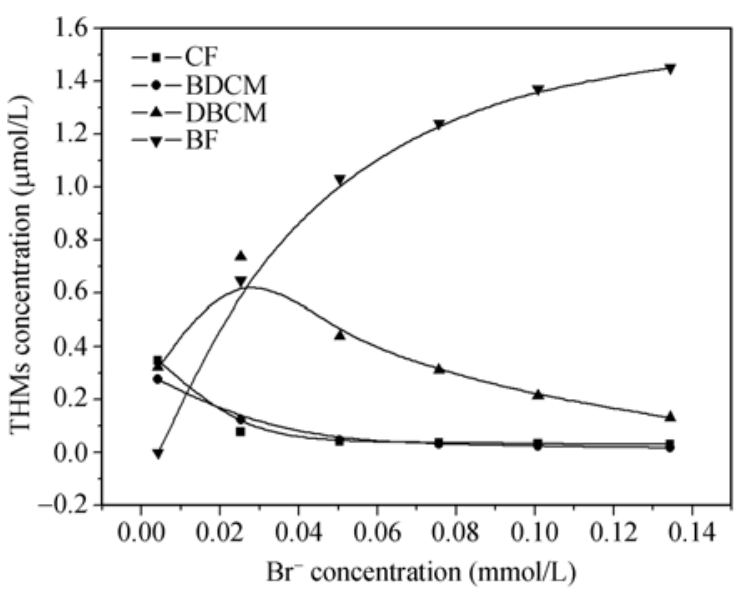

Figure 2 Effect of bromide concentration on formation of THMs species.

concentration of $0.0025 \mathrm{mmol} / \mathrm{L}$. It can be concluded that the bromine ion concentration has important influence on THMs formation and distribution at a constant dose of chlorine. The bromine ion concentration decreased with reaction time resulting in the increase of molar fraction of $\mathrm{CF}$ and BDCM. The dosage of bromide in the experiment was $0.0025 \mathrm{mmol} / \mathrm{L}$. As shown in Figure 2, when bromide concentration was within this range, the molar fraction of DBCM decreased gradually with the decreasing bromide ion concentration and the formation of BF was kept lower. Therefore, it can explain the reduction of molar fraction of DBCM with time and the lower level of BF during the chlorination as shown in Figure 1(b).

The formation of THMs during chlorination generally consisted of two phases: the initial rapid THMs formation and slower long-term THMs formation. To describe the THMs formation quantitatively, a second-order 
model for the long-term formation of THM from the slowly reacting THM precursors (THMFP) is proposed according to the following expression ${ }^{[11]}$ :

$$
\mathrm{Cl}_{2}+\mathrm{THMFP} \stackrel{k}{\longrightarrow} \mathrm{THM}
$$

where [THMFP] is the concentration of the slowly reacting THM precursors $(\mu \mathrm{mol} / \mathrm{L}),\left[\mathrm{Cl}_{2}\right]$ is the concentration of chlorine at time $t(\mu \mathrm{mol} / \mathrm{L})$, and $k$ is the secondorder rate constant of the long-term formation of THMs. Therefore, the rate of THM formation is given by the following equation:

$$
\frac{\mathrm{d}[\mathrm{THM}]}{\mathrm{d} t}=k \times\left[\mathrm{Cl}_{2}\right] \times[\mathrm{THMFP}]
$$

Integrating eq. (1) for $t>t_{\mathrm{i}}\left(t_{\mathrm{i}}=4 \mathrm{~h}\right)$ yields

$$
\begin{aligned}
& \frac{1}{\left(\left[\mathrm{Cl}_{2}\right]_{\mathrm{i}}-[\mathrm{THMFP}]_{\mathrm{T}}\right)} \\
\times & \ln \left(\frac{\left([\mathrm{THMFP}]_{\mathrm{T}} \times\left[\mathrm{Cl}_{2}\right]\right)}{\left[\mathrm{Cl}_{2}\right]_{\mathrm{i}}\left([\mathrm{THMFP}]_{\mathrm{T}}-[\mathrm{THM}]\right)}\right)=k t,
\end{aligned}
$$

where $\left[\mathrm{Cl}_{2}\right]_{\mathrm{i}}$ is the concentration of chlorine after the initial chlorine consumption $(\mu \mathrm{mol} / \mathrm{L}) ; t=t_{\mathrm{i}}(\mathrm{h})$; $[\mathrm{THM}]=$ $\left[\mathrm{THMFP}_{\mathrm{i}}\right](\mu \mathrm{mol} / \mathrm{L})$ and $[\mathrm{THMFP}]_{\mathrm{T}}$ is the total concentration of slowly reacting THM precursors $\left([\mathrm{THMFP}]_{\mathrm{T}}=\right.$ $\left.\left[\mathrm{THMFP}_{\mathrm{f}}\right]-\left[\mathrm{THMFP}_{\mathrm{i}}\right]\right)$. The initial THM formation potential $\left(\mathrm{THMFP}_{\mathrm{i}}\right)$ corresponds to the fast reacting THM precursors formed within the first hours $\left(t<t_{\mathrm{i}}, t_{\mathrm{i}}=4 \mathrm{~h}\right)$. The final THM formation potential $\left(\mathrm{THMFP}_{\mathrm{f}}\right)$ corresponds to the total concentration of THM precursors. The second-order model interpretation of the long-term formation of THMs shows a good linearity $\left(R^{2}>0.99\right)$ and a second-order rate constant of $0.041 \mathrm{~L} /(\mathrm{mol} \cdot \mathrm{h})$.

\subsection{Effect of reaction time on formation and dis- tribution of HAAs}

Figure 3(a) presents the production of five HAAs spe- cies as a function of reaction time. As shown, the formation of HAAs all increased with contact time. However, the formation rate of five HAAs was significantly different. The levels of HAAs species after $24 \mathrm{~h}$ was in the order of TCAA $(72.2 \mu \mathrm{g} / \mathrm{L})>$ DCAA $(27.2 \mu \mathrm{g} / \mathrm{L})>$ DBAA $(6.9 \mu \mathrm{g} / \mathrm{L})>\operatorname{MCAA}(2.0 \mu \mathrm{g} / \mathrm{L})>\operatorname{MBAA}(1.2 \mu \mathrm{g} / \mathrm{L})$. The major HAAs species at $24 \mathrm{~h}$ were chlorinated HAAs (92.6\%), mainly TCAA and DCAA.

To further estimate the formation of HAAs during chlorination, average reaction rate $\Delta C / \Delta t$ for three selected time intervals was used, where $\Delta C=$ (molar concentration at the end of the time interval $\Delta t)-($ molar concentration at the beginning of the time interval $\Delta t$ ), as depicted in Figure 3(b). It can be seen that the formation rate of TCAA was fast $(0.05 \mu \mathrm{mol} / \mathrm{h})$ at the first $4 \mathrm{~h}$ following by DCAA $(0.02 \mu \mathrm{mol} / \mathrm{h})$, whereas the yields of TCAA decreased quickly with time and was only $0.002 \mu \mathrm{mol} / \mathrm{h}$ at the last $12 \mathrm{~h}$. The similar reductive trend was observed for the products of DCAA but the decreasing rate was slower than that of TCAA, with the rate of $0.005 \mu \mathrm{mol} / \mathrm{h}$ at the final $12 \mathrm{~h}$, even faster compared with that of TCAA. The formation of DBAA decreased with time and was lower than that of TCAA and DCAA. The formation of MCAA and MBAA was quite low during $24 \mathrm{~h}$ of chlorination. However, the MCAA increased slightly with time. It was reported that MCAA was the decomposition products of TCAA, BDCAA and $\mathrm{DBCAA}^{[12]}$. Therefore, the formation of MCAA derives not only from the direct pathway of the chlorination reaction with organic matter but also from the indirect pathway of decomposition of TCAA, BDCAA and DBCAA formed initially.

Although the formation rate of HAAs species was different but it is evident that detectable quantity of
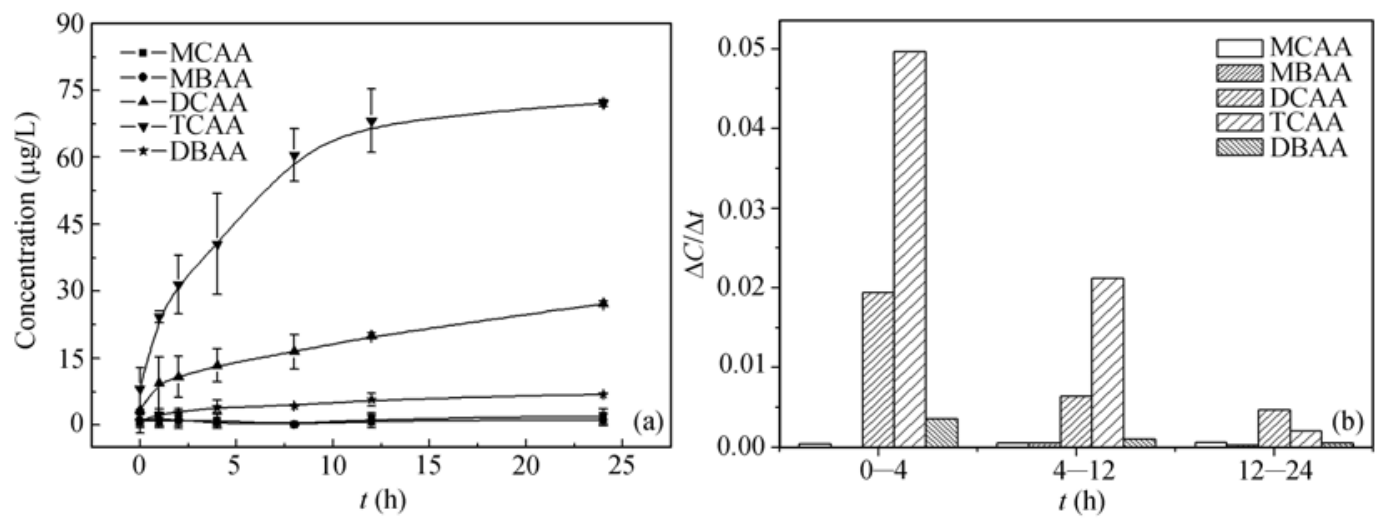

Figure 3 Effect of reaction time on formation and distribution of HAAs species. 
HAAs species were formed at initial hours, whereas BDCM and CF detection was delayed for several hours. This is because the initial substitution of $\mathrm{Cl}$ or $\mathrm{Br}$ into NOM forms relatively high molecular weight halide and the lower molecular compounds such as THMs are not split from the parent molecule until a substantial amount of chlorine and bromine have been incorporated ${ }^{[13]}$. Therefore, part of THMs was not detected at initial hours. It was confirmed by the trend of molar concentration of THMs and HAAs as functions of reaction time (Figure 4). As shown in Figure 4, the yield of HAAs was higher than that of THMs within the first $4 \mathrm{~h}$, however, less HAAs formation after $4 \mathrm{~h}$. This result was consistent with the rate of THMs and HAAs formation during chlorination. As discussed above, the first four hours were the rapid formation phase for both THMs and HAAs. However, THMs formation was in slower long-term period and the formation of HAAs decreased more promptly after $4 \mathrm{~h}$ resulting in the higher molar concentration of THMs compared with that of HAAs after $4 \mathrm{~h}$ of reaction.

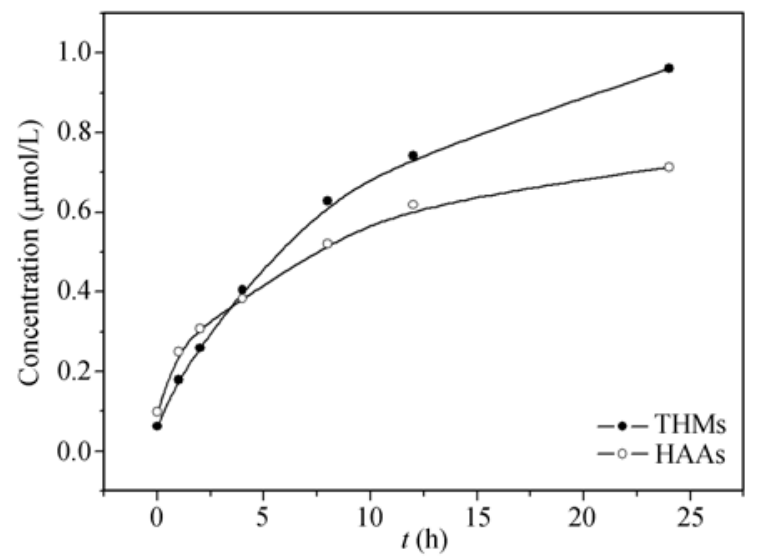

Figure 4 Effect of reaction time on formation of THMs and HAAs.

\subsection{Effect of reaction time on degree of bromine incorporation of THMs and HAAs}

Chlorine and bromine can incorporated into NOM structure by substitute reaction. To access bromine substitution in THMs and HAAs quantitatively, bromine incorporation factor $n$ and $n^{\prime}$ were often used. It can be calculated from the following equation ${ }^{[14]}$.

$$
n=\frac{\sum_{k=0}^{3} k \times\left[\mathrm{CHCl}_{3-k} \mathrm{Br}_{k}\right]}{\sum_{k=0}^{3}\left[\mathrm{CHCl}_{3-k} \mathrm{Br}_{k}\right]},
$$

$$
n^{\prime}=\frac{\{[\mathrm{MBAA}]+[\mathrm{DBAA}] \times 2\}}{\{[\mathrm{MCAA}]+[\mathrm{MBAA}]+[\mathrm{DCAA}]+[\mathrm{TCAA}]+[\mathrm{DBAA}]} \text {. }
$$

The range of $n$ and $n^{\prime}$ was $[0,3]$. An increase in the $n$ and $n^{\prime}$ indicates the formation of more bromine substituted species of THMs and HAAs.

Figure 5 shows the bromine incorporation into THMs and HAAs as a function of reaction time. As shown in Figure 5, the degree of bromine substitute in THMs and HAAs both decreased with time. The extent of bromine incorporation in THMs was higher than that in HAAs. The bromine incorporation factor $n$ decreased from 2.0 to 1.0 and $n^{\prime}$ decreased from 0.17 to 0.10 with the increase of time during $24 \mathrm{~h}$. The chlorinated products were more in the DBPs formation after $24 \mathrm{~h}$ of chlorination. Most of the brominated products were formed at the initial stage and achieved a constant plateau after $24 \mathrm{~h}$.

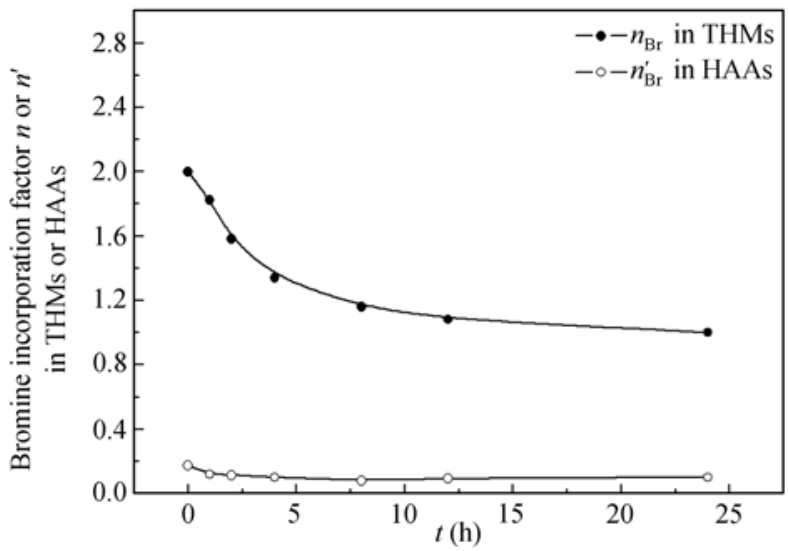

Figure 5 Effect of contact time on the extent of bromine incorporation in THMs or HAAs.

Figure 5 also shows that the substituted extent of bromide in THMs was higher than that in HAAs. A total of nine HAAs including six bromide-containing products would form after chlorination of water containing bromide. In this paper, only two brominated HAAs were investigated. Due to the limits of standard solution and analysis methods of chloro-bromo substitution products, only five of HAAs were regulated by the United States Environmental Protection Agency and studied in this paper. The degree of bromine incorporation of HAAs would be even higher considering other four HAAs containing-bromide (BCAA, BDCAA, DBCAA, TBAA).

\subsection{Effect of $\mathrm{pH}$ value on formation and distribu- tion of THMs}

Figure 6 shows the influence of $\mathrm{pH}$ on the formation and 

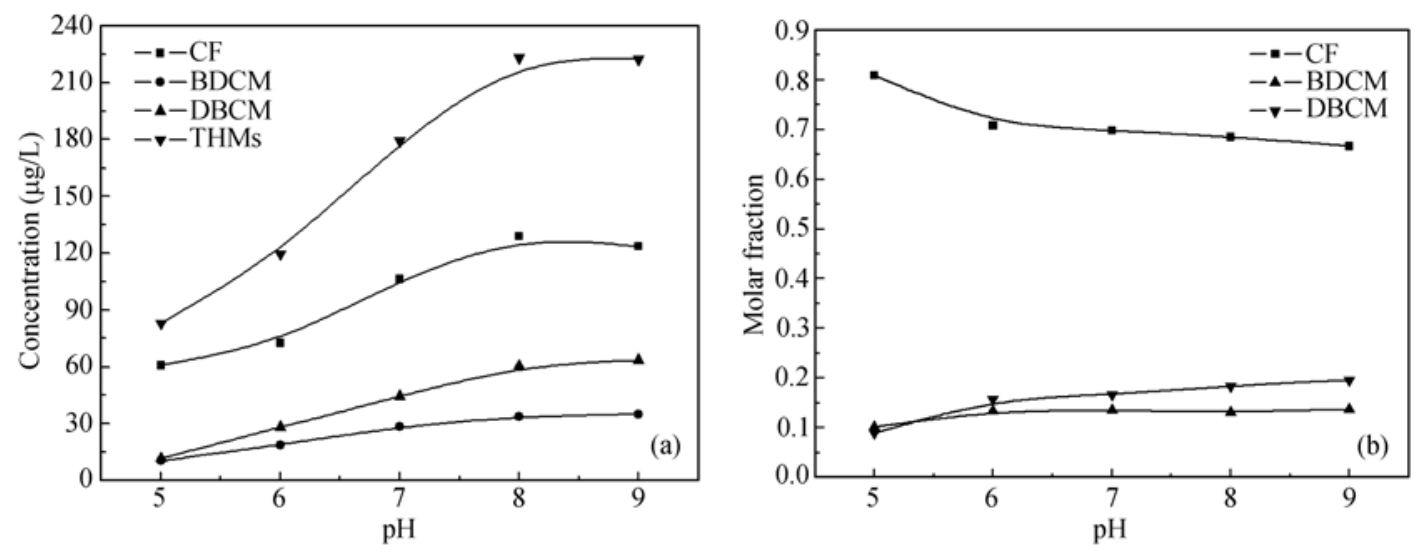

Figure 6 Effect of $\mathrm{pH}$ on formation and distribution of THMs.

distribution of THMs. As shown in Figure 6(a), the production of THMs except the BF that had not been detected all increased with $\mathrm{pH}$ value. The formation of chloroform during the chlorination has been associated with the haloform-type reactions that depend to a much lesser degree upon the rigorous oxidation than does the formation of TCAA. Although the less oxidizing agent $\mathrm{OCl}^{-}$is dominant chlorine species under base condition, the formation of THMs increased with $\mathrm{pH}$ value due to the base-catalysis reaction of halomethane.

As shown in Figure 6(b), the molar fraction of DBCM and $\mathrm{BDCM}$ containing bromide increased with $\mathrm{pH}$ value while CF without bromide decreased. It is generally accepted that humic acid is weakly dissociable acid of which ionization is heavily dependent on $\mathrm{pH}$ value. Humic acid is more hydrophobic in acid solution due to the decreasing solubility at low $\mathrm{pH}$ value. Bromine is more reactive with the hydrophilic fraction in the formation of HAAs and THMs, and chlorine is more reactive with the hydrophobic fraction ${ }^{[15]}$. Therefore, the formation of $\mathrm{CF}$ was relatively higher than that of the bromine-containing THMs with the decrease of $\mathrm{pH}$ value.

\subsection{Effect of $\mathrm{pH}$ value on formation and distribu- tion of HAAs}

Figure 7 demonstrates the effect of $\mathrm{pH}$ value on formation and distribution of HAAs. As shown, increasing the $\mathrm{pH}$ value from 5.0 to 9.0 resulted in a significant reduction of the formation of TCAA from $160.7 \mu \mathrm{g} / \mathrm{L}$ to $79.8 \mu \mathrm{g} / \mathrm{L}$. Unlike the formation of TCAA, that of DCAA is only slightly favored at the low $\mathrm{pH}$ value. When $\mathrm{pH}$ value increased from 5.0 to 9.0, the formation of DCAA reduced from $68.8 \mu \mathrm{g} / \mathrm{L}$ to $37.8 \mu \mathrm{g} / \mathrm{L}$. Although the structures of DCAA and TCAA are similar, it is believed that DCAA does not readily undergo chlorine substitution to form TCAA. It is likely that the immediate precursors to TCAA are trichloroacetyl derivatives. TCAA formation experienced a much more rigorous chlorination-oxidation step than that does DCAA formation, resulting in more complex behavior of TCAA with respect to $\mathrm{pH}$ value ${ }^{[16]}$.

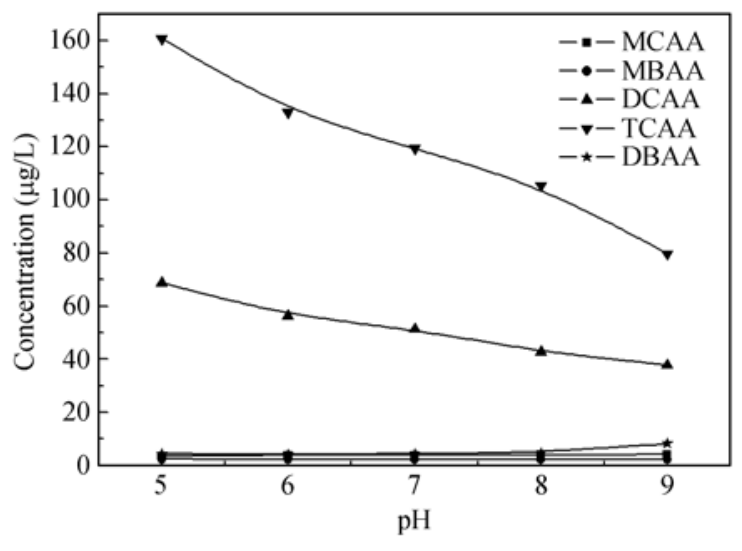

Figure 7 Effect of $\mathrm{pH}$ on formation of HAAs.

The chemistry of chlorine depends on the $\mathrm{pH}$ value. Since hypochlorous acid has a $\mathrm{p} K_{\mathrm{a}}$ of 7.54 , the majority of free chlorine will be in the form of $\mathrm{HOCl}$ at a $\mathrm{pH}$ value lower than 7.54. Because hypochlorous acid is a more powerful oxidizing agent, more highly oxidized chlorinated compounds should prevail at the $\mathrm{pH}$ value where hypochlorous acid predominates. Therefore, the yields of DCAA and TCAA were higher in acidic solution. Increasing $\mathrm{pH}$ value leads to a shift in the chemistry of chlorine from the potent oxidizing agent hypochlorous acid to the less active hypochlorite. Hypochlorite is dominant at a $\mathrm{pH}$ value higher than 7.54, resulting in the reduction of TCAA and DCAA with the increase of $\mathrm{pH}$ value. 
The yields of DBAA, MCAA and MBAA were very low and varied slightly with the increase of $\mathrm{pH}$ value. A hypothesis would be that the activated carbon atom in the $\beta$-diketone moiety $\left(\mathrm{R}^{\prime}-\mathrm{CO}-\mathrm{CH}_{2}-\mathrm{CO}-\mathrm{R}\right)$ is only substituted with one chlorine ( $\left.\mathrm{R}^{\prime}-\mathrm{CO}-\mathrm{CHCl}-\mathrm{CO}-\mathrm{R}\right)$ while it is much more difficult for this structure to hydrolyze to $\mathrm{CH}_{2} \mathrm{Cl}-\mathrm{CO}-\mathrm{R}$ than it is for $\mathrm{R}^{\prime}-\mathrm{CO}-\mathrm{CCl}_{2}-\mathrm{CO}-\mathrm{R}$ to hydrolyze to $\mathrm{CHCl}_{2}-\mathrm{CO}-\mathrm{R}$, which leads to a very low yield of $\operatorname{MCAA}^{[17]}$

\section{Conclusions}

The contact time had important influence on the formation and distribution of trihalomethanes and haloacetic acids. The bromine-containing species comprised a higher molar proportion of the trihalomethanes and the favored products of the haloacetic acids were chlorine-

1 Golfinopoulos S K, Nikolaou A D. Survey of disinfection by-products in drinking water in Athens, Greece. Desalination, 2005, 176: 13-14

2 Cantor K P, Lynch C F, Hildesheim M E, et al. Drinking water source and chlorination by-products I. Risk of bladder cancer. Epidemiology, 1998, 9(1): 21-28

3 Adamantia A K, Euripides G S. The impact of bromide on the formation of neutral and acidic disinfection by-products (DBPs) in Mediterranean chlorinated drinking water. Wat Res, 2002, 36: 2596-2606

4 Grosssman L H, Manka J, Relis B L, et al. Formation and distribution of haloacetic acids, THM and TOX in chlorination of bromide-rich lake water. Wat Res, 1993, 27(8): 1323-1331

5 Westerhoff $\mathrm{P}$, Chao P, Mash H. Reactivity of natural organic matter with aqueous chlorine and bromine. Wat Res, 2004, 38: 1502-1513

6 Rodriguez M J, Serodes J B, Levallois P. Behavior of trihalomethanes and haloacetic acids in a drinking water distribution system. Wat Res, 2004, 38: 4367-4382

7 USEPA. Determination of chlorination disinfection byproducts and chlorinated solvents in drinking water by liquid-liquid extraction and gas chromatography with electron-capture detection. Environmental Monitoring Systems Laboratory Office of Research and Development, Method 551.1, 1990

8 USEPA. Determination of haloacetic acids and dalapon in drinking water by liquid-liquid microextraction derivatization, and gas chromatography with electron capture detection. Technical Support Center Office of Ground Water and Drinking water, Method 552.3, 2003 containing species after $24 \mathrm{~h}$ of chlorination of water containing bromine. The extent of bromine incorporation in trihalomethanes and haloacetic acids both decreased with time.

The formation and distribution of HAAs and THMs strongly depend on the chlorination $\mathrm{pH}$ value. The formation of THMs increased with the increase of $\mathrm{pH}$ value. The molar fraction of $\mathrm{DBCM}$ and BDCM containing bromine increased with $\mathrm{pH}$ value while $\mathrm{CF}$ without bromine decreased with $\mathrm{pH}$ value. Under the $\mathrm{pH}$ range studied in this experiment, the predominant HAAs species were TCAA and DCAA which all decreased with $\mathrm{pH}$ value and the formation of TCAA was higher than that of DCAA. To minimize yields of DBPs, the contact time and $\mathrm{pH}$ value should be optimized during the treatment and transporting process.

9 Nikolaou A D, Lekkas T D, Golfinopoulos S K. Kinetics of the formation and decomposition of chlorination by-products in surface waters. Chem Eng J, 2004, 100: 139-148

10 Chang E E, Lin Y P, Chiang P C. Effects of bromide on the formation of THMs and HAAs. Chemosphere, 2001, 43: 1029-1034

11 Gallard H, Gunten U. Chlorination of natural organic matter: kinetics of chlorination and of THM formation. Wat Res, 2002, 36: 65-74

12 Hozalski R M, Zhang L, Arnold W A. Reduction of haloacetic acids by $\mathrm{Fe}^{0}$ : Implications for treatment and fate. Environ Sci Tech, 2001, 35: $2258-2263$

13 Li C W, Benjamin M M, Korshin G V. Use of UV spectroscopy to characterize the reaction between NOM and free chlorine. Environ Sci Tech, 2000, 34: 2570-2575

14 Gould J P, Fitchhorn L E, Urheim E. Formation of brominated trihalomethanes: Extent and kinetics. In: Jolley R L, ed. Water Chlorination: Environmental Impact and Health Effects. Ann Arbor: Ann Arbor Science Publication, 1983, 4: 297-310

15 Liang L, Singer P C. Factors influencing the formation and relative distribution of haloacetic acid and trihalomethanes in drinking water. Environ Sci Tech, 2003, 37: 2920-2928

16 Reckhow D A, Singer P C, Malcolm R L. Chlorination of humic materials: Byproduct formation and chemical interpretations. Environ Sci Tech, 1990, 24: 1655-1664

17 Gand D. Modeling of THM and HAA formation in Missouri waters upon chlorination. Ph.D. Thesis. Columbia: University of MissouriColumbia, 2001 